\title{
REVIEW OF DIGITAL BADGES IN COMPUTER SCIENCE LITERATURE AND APPLICATIONS
}

\author{
IMRE ZSIGMOND, BEÁTA LŐRINCZ, ANDREA-ÉVA MOLNÁR
}

\begin{abstract}
In the increasingly researched field of gamification, that is the application of the game design elements in no game contexts, one of the most used techniques is the use of digital badges. Through this paper, we conducted a literature review on the use and effectiveness of badges. We include other literature reviews, empirical case studies, and application reports. This analysis shows the widespread use, the different types and specialized nature of digital badges throughout the private and public sectors.
\end{abstract}

\section{INTRODUCTION}

Gamification increasingly gains interest in various e-learning environments. By the most accepted definition, it is the use of game design elements in nongame contexts [12]. This definition, being generic, allows for a wide range of implementations to be classified under it. In practice, game mechanics is the most common implementation method. There are several definitions of game mechanics that have been used in different contexts (e.g. game design [30], analysis [35]). One definition that use concepts from programming is: game mechanics are methods invoked by agents designed for interaction with the game state, thus providing gameplay [43]. The most frequently used game mechanics are: points, badges, leaderboards, and quests.

The earliest usage of gamification elements in the private sector was introduced by airline companies through frequent flyer programs to encourage customers to use the same airline for traveling [38]. Kotlet et al. emphasizes the human desire of achieving goals and being rewarded for achieving these goals. This desire can ultimately be used as a motivational and engagement tool. Based on this principle gamification elements started gaining popularity

Received by the editors: 2 November 2019.

2010 Mathematics Subject Classification. 68-02, 68Q32.

1998 CR Categories and Descriptors. H.5.2 [Information Systems]: User Interfaces - Gamification; A.m [General Literature]: MISCELLANEOUS - Literature review.

Key words and phrases. literature review, achievements, badges, gamification, public sector, private sector. 


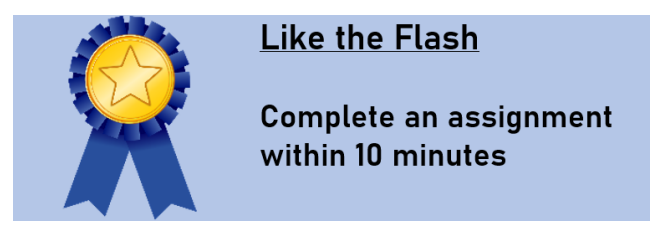

Figure 1. Digital badge example

in different industrial areas where customers were rewarded for transactions, buying products and using the same services repeatedly. In the last decade, enterprises are paying more attention to build and develop tools that use gamification elements in order to enhance the benefits of social software. According to the [47] report, "global gamification market was valued at 6.8 billion USD in 2018 and is projected to grow [...] on account of growing demand for customer experience enrichment and improved engagement of employees."

In this study we analyze digital badges, their usage in solutions for the public and private sectors. By definition, a digital badge - or it's equally used synonym achievement (badge from now on) - is a "representation of an accomplishment, interest or affiliation" and a digital badge in modern context means it's available online and contains information about the process and result of the activity that it is attached to [22]. Aside from the clear description of what it takes to achieve it, badges tend to have a representative image, as well as a title, see Figure 1 for an example. In [27] Hamari states that badges are optional goals and rewards where their fulfillment is outside of the scope of the activity.

One of the main theories behind the persuasiveness of badges is the phenomenon called social comparison [18]. It emerges from people comparing their points and badges as social status or benchmark for themselves. Social comparison theory forms a basis for more specific theories related to comparisons between individuals such as social influence and the theory of planned behavior [3].

Badges by its origins marked subsets of coats of arms and were used to identify outstanding skills or merits [25]. In historical times other symbols of outstanding skills, ranks or accomplishments were medals or trophies granted to individuals considered worthy for the award [22]. Yet another historical use is boy scout badges.

Badges started to appear in video games as these became more advanced [29]. Current mainstream video games tend to all have badges in some form, the mechanic has become ubiquitous in all genres. An inherent advantage of video games is the precision their measurements have when it comes to player behavior. Awarding a badge can be instantaneous and precise. A side effect of 
video game consumption is that audiences get familiar with badges and need less to no onboarding when the same mechanic is used outside of video games. Though, awarding of the badges tend to be slower and less precise unless we have full control over the experience.

Gamification and badges have gained even more interest in education as it is a constant challenge to increase the motivation of learners and enhance their engagement. Several studies focus on the effect of applying gamified elements in education $[22,24,39]$ and discuss the positive and negative effects of their usage. Badges are examined in environments with or without effect on grading emphasizing that the goal is not turning the learning process into a game, but improving the users' interaction, behavior in their education [24] and allowing them to compete with themselves and others. As behavioral outcomes, [39] lists quantifiable goals of education, such as grades, participation and speed in solving tasks.

1.1. Related work. Previous literature reviews tend to focus on the greater concept of gamification, and thus mention badges as a part of the concept or report on exceptional cases of badge use. That being said there are a few articles specializing in badges. [17] focuses on categorization namely in 3 ways: by their function, by their structure, and by design and interaction features. By function, the following subcategories can be distinguished: motivation and engagement, awareness and behavior change, and recognition of achievement. Taking into consideration the design and interaction features, we can identify the following subcategories: visual appeal, badge leader board/dashboard, badge socialization, notification of badges earned, tracking progress and personalization. In terms of their structure, the subcategories are: progressive/milestone, outcomes-based, levelled, categorized, hidden/locked, complex connection structures, starter, and negative. Our own categorization used this paper as a starting point.

To illustrate the importance of badges in gamification, let us consider [39]. In this article, the authors reviewed 128 papers using gamification in an educational context and report that 47 of these use some form of digital badge. In the same paper the authors looked at a subset of 91 papers and report $71.43 \%$ positive, $25.27 \%$ mixed, and a mere $3.3 \%$ negative results. Out of the 91 papers, 39 reported using badges with $64.10 \%$ positive, $30.76 \%$ mixed and $5.12 \%$ negative results. On the result side, [36] found 19 reports of gamified systems pertaining to health and well-being. $59 \%$ reported positive, $41 \%$ mixed effects, with mostly moderate or lower quality of evidence provided. Physical health related behaviors were positive, while the cognitive behaviors were mixed. In [28] the authors analyzed 24 peer-reviewed empirical studies 
on gamification, reporting $13.33 \%$ positive and $86.66 \%$ with mixed results. We notice that out of the 24 studies 9 used badges.

With regards to reporting findings, the authors in [48] chose 14 papers to review, 9 of them used badges. The authors use low level summaries without reporting success rates. Paper [37] provides a high level summary of gamification elements. The author mentions 13 applications that use gamification elements, but does not mention how many of those use badges and specifies that in some implementations, achievements must be awarded manually, e.g. Moodle. In [46], the authors report on a small range of gamification mechanics used. The use of physical badges is also described here (being the only mention of this kind of badges in the reviewed literature) that are awarded on the spot, which are digitized later.

Regarding the discussion of theories, an in depth study on the theories behind gamification is given in [5]. The authors also reports on some case studies of the use of gamification, mentioning badges along the way. In [15], game theory models and formulas were proposed, detailing incentives created by absolute and relative standards.

\section{REVIEW PROCEDURE AND RESEARCH QUESTIONS}

2.1. Review procedure. We conducted a search through Google Scholar, Scopus, IEEE and Web of Science databases and selected literature review articles that summarize studies performed on the applications of badges in educational and other learning environments. The keywords used in the search were: "gamification", "badges", "digital badges", "achievements", "achievement badges" and "game mechanics". We chose a number of 32 conference papers, articles or book chapters. This number includes all the reviewed studies, the ones originally chosen based on the search results and papers referenced by these. While this selection is nowhere complete (the Scopus, IEEE and Web of Science databases returned a few hundred results with Google Scholar reaching a number of 150.000 results), it is indicative of the literature on our queries. In addition to the reviewed studies, our procedure included an analysis of applications that use badges. The main focus in the selection was to find frequently used apps that use badges, and to cover a wide range of application fields that these are utilized in. While there are a high number of applications that implement badges we only selected applications that we found referenced in the academic literature. We selected 11 applications mentioned in conference papers or articles covering 4 different types of application fields that deal with the role and effectiveness of badges.

2.2. Research questions. When we set out to conduct this literature review, we were interested in 3 main aspects of badges: 
(1) What types of badges are used or defined?

(2) What were the results of implementing badges in various contexts?

(3) What applications used badges and how?

Our findings are detailed in Sections 3.1, 3.2, and 3.3 respectively.

\section{Literature REVIEW}

3.1. Badge types. Badges can be categorized based on different criteria such as function, structure or design elements [17]. Other criteria is the application area or customized features that are unique to the conducted experiment. Badges can be assigned to multiple categories within the same criteria. In this section we list the categorization criteria and types reported in the reviewed literature with mentioning that some studies do not detail the badge specifics, therefore some of the categorizations were inferred.

The badge function that is emphasized the most is: motivation, the engagement of users in the activity that uses gamified elements $[16,27,39]$. Other functions mentioned by studies are behavioral changes, awareness and the recognition of achievements [17].

To achieve these functions several structural features were conceptualized and implemented for badge systems. Table 1 summarizes the badge types based on their structure, including the types that were found in the reviewed literature.

In addition to the badge types listed in Table 1, [1] considered two distinct models for educational badges: merit badges and video game achievements. [9] study presents permanent and temporary badges, temporary badges being refreshed fortnightly. A somewhat unique mention of a badge system appears in [46], where the author reports on physical badges in the form of cards handed out on the spot which could be digitized later. [41] analyzes topic badges, that can be also considered simple badges as they can be earned by solving a set of exercises related to a specific topic. The same study reports on repetitive badges that can be seen as progressive, respectively challenge badges at the same time as several exercises need to be solved correctly in a row, but also rapidly. In [16], participation, attendance and flowchart badges were applied in educational environments for programming courses.

Badges are categorized based on their design features, the implementation of the system. The design of the badges, the used colors and symbols have an impact on users engagement. The interaction features, such as notification types, visual presentation, tracking tools, also influence the user experience [17].

Badges differ in terms of the fields of their applications. The majority of reviewed articles concentrate on badge usage in educational environments, 
IMRE ZSIGMOND, BEÁTA LŐRINCZ, ANDREA-ÉVA MOLNÁR

\begin{tabular}{|c|c|c|c|}
\hline Type & Description & Example & Used in \\
\hline $\begin{array}{l}\text { Simple } \\
\text { badges }\end{array}$ & $\begin{array}{l}\text { Easily obtainable, out- } \\
\text { come based. }\end{array}$ & $\begin{array}{l}\text { Complete first as- } \\
\text { signment. }\end{array}$ & $\begin{array}{l}{[2,8,11,14,} \\
19,24,26, \\
27,41]\end{array}$ \\
\hline $\begin{array}{l}\text { Progressive } \\
\text { (milestone, } \\
\text { streak) } \\
\text { badges }\end{array}$ & $\begin{array}{l}\text { Assigned to users based } \\
\text { on a metric that defines } \\
\text { milestones representing } \\
\text { the progress. Users are } \\
\text { granted these badges } \\
\text { if correct solutions are } \\
\text { given to tasks consecu- } \\
\text { tively. }\end{array}$ & $\begin{array}{l}\text { Complete first } \\
\text { five assignments. }\end{array}$ & $\begin{array}{l}{[6,8,19,26,} \\
27]\end{array}$ \\
\hline $\begin{array}{l}\text { Hidden } \\
\text { badges }\end{array}$ & $\begin{array}{l}\text { Users are unaware of } \\
\text { their existence until the } \\
\text { badge is granted to them. }\end{array}$ & Easter egg & {$[11,24]$} \\
\hline $\begin{array}{l}\text { Locked } \\
\text { badges }\end{array}$ & $\begin{array}{l}\text { Badges are visible, but } \\
\text { locked for users until the } \\
\text { conditions for obtaining } \\
\text { these are not fulfilled. }\end{array}$ & $\begin{array}{l}\text { Khan Academy: } \\
\text { Black hole }\end{array}$ & {$[23,27]$} \\
\hline $\begin{array}{l}\text { Challenge } \\
\text { badges }\end{array}$ & $\begin{array}{l}\text { Users can achieve these } \\
\text { badges if the tasks are } \\
\text { solved with features that } \\
\text { have an increased diff- } \\
\text { culty. }\end{array}$ & $\begin{array}{l}\text { Complete assign- } \\
\text { ment within } 10 \\
\text { minutes. }\end{array}$ & {$[8,14,26]$} \\
\hline $\begin{array}{l}\text { Negative } \\
\text { badges }\end{array}$ & $\begin{array}{l}\text { These badges can be } \\
\text { assigned to users if an } \\
\text { activity was not com- } \\
\text { pleted within the speci- } \\
\text { fied criteria. }\end{array}$ & $\begin{array}{l}\text { Did not deliver } \\
\text { activity. }\end{array}$ & {$[42]$} \\
\hline $\begin{array}{l}\text { Not specified } \\
\text { (Custom) }\end{array}$ & $\begin{array}{l}\text { Badge specifications not } \\
\text { provided. }\end{array}$ & & {$[16,46]$} \\
\hline
\end{tabular}

TABLE 1. Badge types

that can be considered as part of the public sector. In addition, badge systems available online for any users can be seen as part of the public sector as well. Badge systems used in industrial settings (where the employees of the industrial organization are the users) can be considered as part of the private sector. 


\begin{tabular}{|c|c|}
\hline Effect & Studies \\
\hline Positive & {$[2,7,8,10,16,19,20,27,32]$} \\
\hline Mixed & {$[1,6,11,14,41]$} \\
\hline Negative & {$[24,26,33,40]$} \\
\hline
\end{tabular}

TABLE 2. List of papers by reported outcomes

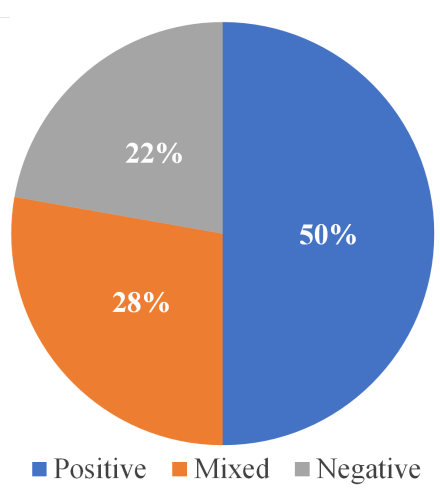

FiguRE 2. Overview of reported results in the papers

Some of the categorizations discussed fall squarely in domain specific categories. From the perspective of empirical research, we find that the more specific types detailed in Table 1 are to be considered.

3.2. Reported results. For the empirical case studies that we analyzed, 3 categories of success were chosen (see Table $2 \&$ Figure 2). The threshold was based on the author's self-reporting on a given paper. Studies with a clear majority of positive findings would be classified as such, the same for negative result, while all studies with no clear positive or negative reported results, or a similar number of positive and negative reported results would be classified as mixed results. What follows are short summaries of the case studies.

The following studies reported positive results. In [2], high school students were the subjects of an online vocabulary study group. The authors report an increase of the study time and number of memorized words, but we need to take into consideration the lack of control groups. In [8] a computer engineering master's level college course was gamified. In comparison to the previous year, authors have reported $511 \%$ to $845 \%$ increase in forum engagement, while the increment in the case of faculty's forum activity was $373 \%$. Grades did not increase compared to the previous year, only student engagement. Orientation passport app [19] used badges to direct attention to various events and locations useful for a first-year college student. Activities involved going to places/events taking pictures of QR codes or adding people from the peer group. Survey suggested positive student attitude towards the activities. The findings of [16] state that the participation and flowchart badges motivated users, while the attendance badges were not highly valued 
by students. In [10], the authors highlighted that badges are valuable in stimulating voluntary participation. In [7], the authors establish from empirical data that users indeed value badges and modify their site activities to earn badges, and propose a model of how a user splits his/her time across various possible actions on a site (such as asking, answering, voting), in response to badges that are awarded for these actions. Paper [20] presents a gamified data structures course, with the use of badges. Although, badges did not have a direct impact on the final grade nevertheless it did increase the student's course grade. Positive effects were also found on task submission and trial and error submissions. The attractiveness of badges in Duolingo was analyzed in [32]. Concentrating on the platform's milestones, the authors found a positive statistically significant but lower than expected correlation between badges and progress.

The following studies reported mixed results. In [6], the authors tried two tracks of the same course: one started with badges and gamification, while the other without. At the halfway point, they switched the settings for both groups. They reported a slight increase in activity for "no gamification to gamification" group, while in the case of the activity for the "gamification to no gamification" group a moderate decrease was observable. They had no control groups of either gamification or no gamification only, to compare against. Although, overall grades appeared to be similar for both groups. In [11], a competition focused gamification experiment was set against a cooperation based social network, and a control group in a basic computer knowledge course. While performance was similar for all 3 groups, in Word and Excel gamification trailed behind both other groups. In the case of [14], the authors created an achievement add-on to an existing e-learning platform with an opt in system and a control group. Achievements were awarded manually and results were mixed with the authors reporting no theory as to why. Paper [41] described a specific badge usage metric and the usage of this metric on a group of engineering students. The authors divided students into 3 groups, based on an unsupervised clustering method: the first two groups included students who put the most effort, respectively students who made low effort, while the students who invested a decent amount of work but without many results were placed into the third group. In their study, Hamari reports mostly positive results and state that, depending on the type badges, badges had a positive effect on the practical assignments, but negative effects on written assignments [27]. The authors mention that a potential problem is the excessive usage of badges. In [1], the authors discovered that there is a connection between students' prior knowledge and how they value the obtained badges. 


\begin{tabular}{|l|l|l|}
\hline Context/field & Applications & $\begin{array}{l}\text { Papers con- } \\
\text { cerning } \\
\text { applications }\end{array}$ \\
\hline $\begin{array}{l}\text { Education and } \\
\text { learning }\end{array}$ & $\begin{array}{l}\text { Khan Academy, Codeacademy, } \\
\text { Duolingo }\end{array}$ & {$[13,31-34,50]$} \\
\hline Sustainability & Joule Bug & {$[4]$} \\
\hline Health/exercise & FitBit $^{2}$, Samsung Health, Fitocracy & {$[45,49]$} \\
\hline $\begin{array}{l}\text { Community/ } \\
\text { sharing }\end{array}$ & $\begin{array}{l}\text { Google Maps, Tripadvisor, } \\
\text { Foursquare }^{3} \text {,Stack Overflow }\end{array}$ & {$[10,21,38,44]$} \\
\hline
\end{tabular}

TABLE 3. Reviewed applications using badges

The following studies reported no or negative effects. In [26], the authors implemented a badge system on a purely utilitarian trading service, checking whether badge visibility affected the results. Their results showed that badges had no effect on how their application was used, concluding that likely more hedonistic contexts favor gamification. The study [24] on an online learning environment reported no significant difference between the experimental and control groups, and mentioned that some of the badges encouraged unwanted behavior. The authors of [40] discuss the contribution of badges to grades as negative effects as students reported frustrations because part of their grades depended on the collected badges. In [33], the authors analyzed two game elements - Badge and Winning Streak - with respect to the foreign language learning application, Duolingo ${ }^{1}$. The authors show that advanced users find badges less interesting.

3.3. Applications. Nowadays more and more companies incorporate the notion of gamification into their mobile apps and web pages. We reviewed several popular and interesting applications that use gamification techniques, focusing on the applications that award the users with badges. In Table 3, we included a summary of the selected applications and their associated literature, grouped by the field where they are used.

Rewarding the completion of learning tasks in educational environments is considered a game action. Therefore, learning applications award users with badges mostly to encourage them to complete the given tasks and to use the application regularly.

\footnotetext{
${ }^{1}$ https://www.duolingo.com

${ }^{2}$ https://www.fitbit.com

3 https://foursquare.com/
} 
Khan Academy ${ }^{4}$ is a learning website, which uses video lessons to teach different topics for users. Users receive rewards for watching instructional videos, answering questions and resolving quizzes in the form of badges ${ }^{5}$. In Khan Academy hundreds of different badges are available, separated into 5 different tiers: Meteorite (including the most common, i.e. the most easily obtainable badges), Moon, Earth, Sun, Black Hole (including the rarest, i.e. the most hardly obtainable badges). Five is Alive! is a meteorite badge that can be earned by finishing five practice tasks, while Incredible Question is an Earth Badge and it can be achieved by asking a question that earns $50+$ votes. Khan Academy also provides streak badges, which can be achieved by consecutively answering correctly to a certain number of questions (e.g. Ludicrous Streak is a Moon badge, which can be earned if 100 correct answers are submitted consecutively for any type of exercise). This application also includes some subject-specific badges (e.g. Computer Science badges that can be achieved by completing tasks in the Computer Science subject). As a user finishes certain course units, tutorials, or special activities, he/she is rewarded with Challenge Patches (e.g. Intro to SQL: Querying and managing data is a challenge patches badge, which can be collected if a user completes all the 'Intro to SQL' challenges).

Codeacademy ${ }^{6}$ is also a learning website that teaches computer science. Codeacademy uses badges in order to track the progress of learners and to encourage perseverance. Codeacademy uses 4 types of badges. A learner can get an exercise badge when completes a specific number of exercises (e.g. 10 exercises). Course badges can be collected completing lessons that do not have a specific badge (e.g. Rails Achievement badge can be achieved by completing Ruby on Rails lessons), while course-specific badges are connected to particular lessons or courses (e.g. Functions in JavaScript badge). There are also promotion badges which are connected to an event or a partnership (e.g. 404 badge).

In recent years foreign language learning applications have become widespread. Duolingo is one of the most popular educational gamified languagelearning platforms, which uses several gamification elements in order to help users enhance their regular learning activity. Duolingo includes several badges (e.g. Champion, Wildfire), each of them comes in tiers (e.g. in the case of Champion badge the first, second, respectively the third tier are finished if the user completes 10, 20 skills, respectively a language tree).

\footnotetext{
${ }^{4}$ https://www.khanacademy.org

${ }^{5}$ https://www.khanacademy.org/badges

${ }^{6}$ https://www.codecademy.com
} 
The number of applications and companies which try to draw attention to several important aspects of life, for example the importance of reading, environmental awareness or healthy lifestyle, has increased dramatically. Badges are widely used in health and fitness applications, trying to influence positive changes in users' health behaviors. We analyzed two fitness applications, which use gamification elements. Fitocracy ${ }^{7}$ offers streak badges (e.g. Get Low, Monster Squat) and achievement badges. These badges are earned for various activities (e.g. Let's get outta here is given after $100 \mathrm{~km}$ cycling). Samsung Health ${ }^{8}$ includes reward badges, which are earned if a user completes a goal or he/she breaks his/her own record in an activity (e.g. Best Pace breaking our best pace in walking).

Nowadays, environmental awareness and sustainable development are playing an increasingly important role in our daily lives. Joule $b u g^{9}$ is an application which uses achievements in order to encourage people to make small changes in their behaviors in all aspects of sustainability, therefore to pursue an environmentally conscious lifestyle.

The use of gamification for loyalty programs and customer communities is also gaining popularity. In loyalty programs, customers can collect reward points that can be redeemed, while in any type of community customers can be motivated with reputation points, also called badges. Depending on the type of contribution (e.g. sharing photos of places, reviewing a place), in the web mapping service Google Maps ${ }^{10}$ (developed by Google) users can collect different types of badges: Reviewer, Photographer, Director, Trailblazer, Fact Finder. There are 3 levels available for each type: novice, expert and master. By sharing and contributing more users can upgrade their badges to a higher level.

Tripadvisor ${ }^{11}$ is the world's largest travel portal, where travelers can plan and book almost everything for their next trip (accommodation, guiding tours etc.), and share their experiences (by reviews). Tripadvisor provides TripCollective badges ${ }^{12}$ for appreciating the users' contributions to the travel community and for illustrating their expertise and assistance to other users (e.g. Explorer badge can be collected for writing the first review for a restaurant, hotel or attraction in a given language).

\footnotetext{
${ }^{7}$ https://www.fitocracy.com/

${ }^{8}$ https://www.samsung.com/us/samsung-health/

${ }^{9}$ https://joulebug.com

10 https://www.google.com/maps

${ }^{11}$ https://www.tripadvisor.com/

${ }^{12}$ https://www.tripadvisor.com/TripCollectiveBadges
} 
The number of websites and applications that incorporated badges in order to reflect the real skills of their users has increased in recent years. This is due to the fact that these companies have recognized that these skills are exactly the ones that employers and schools are looking for. Stackoverflow ${ }^{13}$, the online developer community, realized that the individual responses indicate the skill level of the users, so they created a badge system. There are 6 types of badges (over 80 different badges): question, answer, participation, tag, moderation, other badges. These badges are organized into 3 categories (bronze, silver and gold), depending on how easily they can be obtained. For example, the Scholar question badge can be earned very easily: if someone asks a question and accepts an answer. However, the Mortarboard badge (gold, participation badge) can be collected only if a user earns 200 daily reputation 150 times. $^{14}$

We can notice that application badges are most often used in learning environments, respectively in crowd-sourcing systems.

\section{Discussions and Conclusions}

Digital badges have emerged in various tools and learning environments, both in the public and private sectors. They aim to increase user engagement and to motivate users to change their behavior and enhance their skills. In our paper we have proposed to answer 3 research questions. The first refers to the types of badges used. Out of the 32 studies reviewed, 17 mentioned the type of badge used. The categorization criteria varies in these studies, where all of these principles are associated with the function, structure, application domain or design elements of badges. The most frequently used criteria is concerned with the structure of the badges, in which we have discussed 7 different badge types. The second question is to evaluate the results of implementing badges in various contexts. Out of the 32 articles 18 reported positive, negative or mixed results, with 9 mentioning positive and only 5 negative results. These were evaluated by analyzing the functions and effects of badges in relation to the user experience. While using badges, generally positive results may be expected, depending on the circumstances and badges used, mixed or negative results may be assumed, although rarely. Research is so far inconclusive on the why and when, mixed or negative results are expected, current theories seem untested. The third question was focused on the badge usage in applications. We have tested 11 applications that use badges and are mentioned in academic literature. The primary fields of applications are: education, health

\footnotetext{
13 https://stackoverflow.com/

${ }^{14}$ https://stackoverflow.com/help/badges
} 
and community. Badge systems are used in a wide range of applications, and it is gaining more and more interest as it aims to improve user engagement.

More research is required for analyzing the circumstances and features of badges that lead to different results. Most of the specifics of the badge design is not reported in various studies making research on the topic less precise than desired.

\section{REFERENCES}

[1] S. Abramovich, C. Schunn, and R. M. Higashi. Are badges useful in education?: It depends upon the type of badge and expertise of learner. Educational Technology Research and Development, 61(2):217-232, 2013.

[2] S. S. Abrams and S. Walsh. Gamified vocabulary. Journal of Adolescent \& Adult Literacy, 58(1):49-58, 2014.

[3] I. Ajzen. The theory of planned behavior. Organizational behavior and human decision processes, 50(2):179-211, 1991

[4] D. Akbulut and G. Yıldırım. The usage of green gamification for public interest function of public relations. CTC 2019, 2019.

[5] R. S. Alsawaier. The effect of gamification on motivation and engagement. The International Journal of Information and Learning Technology, 35(1):56 - 79, 2018.

[6] A. Amriani, A. F. Aji, A. Y. Utomo, and K. M. Junus. An empirical study of gamification impact on e-learning environment. In Proceedings of 2013 3rd International Conference on Computer Science and Network Technology, pages 265 - 269. IEEE, 2013.

[7] A. Anderson, D. Huttenlocher, J. Kleinberg, and J. Leskovec. Steering user behavior with badges. In Proceedings of the 22nd International Conference on World Wide Web, pages 95-106. ACM, 2013.

[8] G. Barata, S. Gama, J. Jorge, and D. Gonçalves. Engaging engineering students with gamification. In 2013 5th International Conference on Games and Virtual Worlds for Serious Applications (VS-GAMES), pages 1-8. IEEE, 2013.

[9] S. K. Bista, S. Nepal, N. Colineau, and C. Paris. Using gamification in an online community. In 8th International Conference on Collaborative Computing: Networking, Applications and Worksharing (CollaborateCom), pages 611-618. IEEE, 2012.

[10] H. Cavusoglu, Z. Li, and K.-W. Huang. Can gamification motivate volun-tary contributions?: the case of Stackoverflow Q\&A community. In Proceedings of the 18th ACM Conference Companion on Computer Supported Cooperative Work \& Social Computing, pages 171-174. ACM, 2015.

[11] L. De-Marcos, A. Domínguez, J. Saenz-de Navarrete, and C. Pagés. An empirical study comparing gamification and social networking on e-learning. Computers $\mathcal{E}$ Education, $75: 82-91,2014$

[12] S. Deterding, D. Dixon, R. Khaled, and L. Nacke. From game design elements to gamefulness: Defining gamification. In Proceedings of the 15th international academic MindTrek conference: Envisioning future media environments, volume 11, pages 9 - 15 . ACM, 2011.

[13] B. J. DiSalvo and B. B. Morison. Khan Academy gamifies computer science. In Proc. 45th ACM Techn. Symp. Comput. Sci. Educ., pages $39-44,2014$. 
[14] A. Domínguez, J. Saenz-De-Navarrete, L. De-Marcos, L. Fernández-Sanz, C. Pagés, and J.-J. Martínez-Herráiz. Gamifying learning experiences: Practical implications and outcomes. Computers \& Education, 63:380-392, 2013.

[15] D. Easley and A. Ghosh. Incentives, gamification, and game theory: An economic approach to badge design. ACM Trans. Econ. Comput., 4(3):16:1 - 16:26, 2016.

[16] L. Facey-Shaw, M. Specht, and J. Bartley-Bryan. Digital badges for motivating introductory programmers: Qualitative findings from focus groups. In 2018 IEEE Frontiers in Education Conference (FIE), pages 1-7, Oct 2018.

[17] L. Facey-Shaw, M. Specht, P. van Rosmalen, D. Brner, and J. Bartley-Bryan. Educational functions and design of badge systems: A conceptual literature review. IEEE Transactions on Learning Technologies, 11(4):536 - 544, 2018.

[18] L. Festinger. A theory of social comparison processes. Human relations, 7(2):117-140, 1954.

[19] Z. Fitz-Walter, D. Tjondronegoro, and P. Wyeth. Orientation passport: Using gamification to engage university students. In Proceedings of the 23rd Australian ComputerHuman Interaction Conference, OzCHI '11, pages 122 - 125, New York, NY, USA, 2011. ACM.

[20] J. Fresno, H. Ortega-Arranz, A. Ortega-Arranz, A. Gonzalez-Escribano, and D. R. Llanos. Applying gamification in a parallel programming course. In Gamification in Education: Breakthroughs in Research and Practice, pages 278-302. IGI Global, 2018.

[21] J. Frith. Turning life into a game: Foursquare, gamification, and personal mobility. Mobile Media ES Communication, 1(2):248-262, 2013.

[22] D. Gibson, N. Ostashewski, K. Flintoff, S. Grant, and E. Knight. Digital badges in education. Education and Information Technologies, 20(2):403 - 410, 2015.

[23] L. Haaranen, L. Hakulinen, P. Ihantola, and A. Korhonen. Software architectures for implementing achievement badges - practical experiences. In 2014 International Conference on Teaching and Learning in Computing and Engineering, pages 41-46, April 2014.

[24] L. Hakulinen, T. Auvinen, and A. Korhonen. Empirical study on the effect of achievement badges in TRAKLA2 online learning environment. In 2013 Learning and teaching in computing and engineering, pages 47-54. IEEE, 2013.

[25] A. M. Halavais. A genealogy of badges: Inherited meaning and monstrous moral hybrids. Information, Communication \& Society, 15(3):354 - 373, 2012.

[26] J. Hamari. Transforming homo economicus into homo ludens: A field experiment on gamification in a utilitarian peer-to-peer trading service. Electronic Commerce Research and Applications, 12(4):236 - 245, 2013. Social Commerce- Part 2.

[27] J. Hamari. Do badges increase user activity? A field experiment on the effects of gamification. Computers in human behavior, 71:469 - 478, 2017.

[28] J. Hamari, J. Koivisto, H. Sarsa, et al. Does gamification work? - A literature review of empirical studies on gamification. In HICSS, volume 14, pages 3025-3034, 2014.

[29] K. Hilliard. Activision badges - the original gaming achievement (2013, october 23). Retrieved October, 2019, from Game Informer:

https://www.gameinformer.com/b/features/archive/2013/10/26/activision-badgesthe-original-gaming-achievement.aspx.

[30] R. Hunicke, M. LeBlanc, and R. Zubek. Mda: A formal approach to game design and game research. In Proceedings of the AAAI Workshop on Challenges in Game AI, volume 4, page 1722, 2004. 
[31] D. Huynh and H. Iida. An analysis of winning streak's effects in language course of "Duolingo". Asia-Pacific Journal of Information Technology and Multimedia, 6(2), 2017.

[32] D. Huynh, L. Zuo, and H. Iida. Analyzing gamification of "Duolingo" with focus on its course structure. In International Conference on Games and Learning Alliance, pages 268-277. Springer, 2016.

[33] D. Huynh, L. Zuo, and H. Iida. An Assessment of Game Elements in Language-Learning Platform Duolingo. In 2018 4th International Conference on Computer and Information Sciences (ICCOINS), pages 1-4. IEEE, 2018.

[34] M.-B. Ibanez, A. Di-Serio, and C. Delgado-Kloos. Gamification for engaging computer science students in learning activities: A case study. IEEE Transactions on learning technologies, 7(3):291-301, 2014.

[35] A. Järvinen. Games without frontiers: Theories and methods for game studies and design. Tampere University Press, 2008.

[36] D. Johnson, S. Deterding, K.-A. Kuhn, A. Staneva, S. Stoyanov, and L. Hides. Gamification for health and wellbeing: A systematic review of the literature. Internet interventions, 6:89-106, 2016.

[37] G. Kiryakova, N. Angelova, and L. Yordanova. Gamification in education. In Proceedings of 9th International Balkan Education and Science Conference, 2014

[38] P. Kotler, H. Kartajaya, and I. Setiawan. Marketing 4.0: Moving from traditional to digital. John Wiley \& Sons, 2016.

[39] K.-J. Majuri, Jenni and J. Hamari. Gamification of education and learning: A review of empirical literature. In Proceedings of the 2nd International GamiFIN Conference, GamiFIN 2018. CEUR-WS, 2018.

[40] R. McDaniel, R. Lindgren, and J. Friskics. Using badges for shaping interactions in online learning environments. In 2012 IEEE International Professional Communication Conference, pages 1-4, Oct 2012.

[41] J. A. Ruipérez-Valiente, P. J. Muñoz-Merino, and C. Delgado Kloos. Detecting and clustering students by their gamification behavior with badges: A case study in engineering education. International Journal of Engineering Education, 33(2-B):816 - 830, 2017.

[42] L. Seixas, A. Gomes, and I. Melo Filho. Effectiveness of gamification in the engagement of students. Computers in Human Behavior, 58:48-63, 2016.

[43] M. Sicart. Defining game mechanics. Game Studies, 8(2):n, 2008.

[44] M. Sigala. The application and impact of gamification funware on trip planning and experiences: The case of tripadvisorś funware. Electronic Markets, 25(3):189-209, 2015.

[45] R. Stålnacke Larsson. Motivations in sports and fitness gamification: A study to understand what motivates the users of sports and fitness gamification services, 2013.

[46] A. Stott and C. Neustaedter. Analysis of gamification in education. Surrey, BC, Canada, 8:36, 2013.

[47] TechSci Research. Global gamification market by solution, by deployment, by organization size, by application, by end-user vertical, by region, competition, forecast \& opportunities, 2024. TechSci Research, 2019.

[48] M. M. Tenório, F. A. F. Reinaldo, L. A. Góis, R. P. Lopes, and G. dos Santos Junior Elements of gamification in virtual learning environments. In International Conference on Interactive Collaborative Learning, pages 86-96. Springer, 2017.

[49] Á. Tóth and E. Lógó. The effect of gamification in sport applications. In 2018 9th IEEE International Conference on Cognitive Infocommunications (CogInfoCom), pages 69-74. IEEE, 2018. 
[50] R. van Roy, S. Deterding, and B. Zaman. Collecting Pokémon or receiving rewards? How people functionalise badges in gamified online learning environments in the wild. International Journal of Human-Computer Studies, 127:62-80, 2019.

All authors are with the Faculty of Mathematics and Computer Science, Babeș-Bolyai University, 1 Mihail Kogălniceanu, RO-400084 Cluj-Napoca, RoMANIA

Email address: imre@cs.ubbcluj.ro and lorinczb@cs.ubbcluj.ro and andrea.molnar@math.ubbcluj.ro 